\title{
Overview of the treatment for borderline personality disorder
}

Karthikeyan Veerasamy, Latha Guruvaiah

\section{Summary}

Borderline personality disorder (BPD) is a relatively new concept whichhas received much attention recently. In ICD10, emotionally unstable personality disorder, is subcategorised as impulsive type and borderline type. According to DSM IV diagnosis of BPD requires at least five out of nine features. Antipsychotics is effective in reducing affective instability, anger and psychotic symptoms. Beneficial effects were found with mood stabilisers such as semisodium valproate, lamotrigine and topiramate, but not carbamazepine. Psychological treatment is considered as first line treatment for borderline patients but the evidence is not extensive for most of the therapies except for dialectical behavioural therapy.

SL J Psychiatry 2013; 4 (2) 11-15

\section{Introduction}

Borderline personality disorder (BPD) is a relatively new concept and interest has grown in the last two or three decades. It was included as a diagnostic category for the first time in DSM III. Since then there has been increasing awareness and recognition of BPD among professionals which has led to more patients being diagnosed with this condition especially in the Western countries. However it is still under recognised in developing countries for reasons which are beyond the scope of this article. Even if it is recognised, providing treatment is difficult due to poor funding and poor availability of resources.

The term "borderline personality disorder" was first coined by the American psychoanalyst Adolf Stern in 1938 to describe a condition, in between the psychoses and neuroses (1).

BPD is characterised by a pervasive pattern of affective dysregulation (inappropriate anger, chronic feelings of emptiness and affective instability), impulse control (self-mutilation, suicidal behaviour and ideation, or threatening suicide), interpersonal problems (frantic efforts to avoid abandonment, patterns of unstable relationships with idealisation and/or depreciation of others) and cognitive-perceptual problems (identity disturbance in terms of self perception, transient paranoid thoughts or feelings of dissociation in stressful situations) (2). It is also associated with substantial impairment of social, psychological and occupational functioning and poor quality of life. People with BPD are particularly at risk of suicide.

The prevalence of BPD is estimated to be $1.5 \%$ in the general population and $20 \%$ among inpatients $(3,4)$. It is predominantly diagnosed in women (75\%) (5). BPD commonly co-occurs with mood disorders, substance misuse, eating disorders, post traumatic stress disorder and other personality disorders (6). Suicidal behaviour is reported in $84 \%$ of patients with BPD (7). Co-morbid mood disorders or substance use are common risk factors for completed suicide (8).
People with BPD often present to emergency departments after self-harming or in suicidal crises, and have a history of repeated hospitalisation. Treatment facilities and settings for management of patients vary between countries. Pharmacological interventions are increasingly used to treat different facets of psychopathology, such as affective instability, impulsivity, dissociative states or cognitive-perceptual symptoms (9). Associated disorders such as depression can also be treated with medicines (10).

\section{Diagnostic criteria for borderline personality disorder}

In ICD10, emotionally unstable personality disorder, is subcategorised as impulsive type and borderline type. According to DSM IV diagnosis of BPD requires at least five out of nine features to be present. These features are; frantic efforts to avoid abandonment, unstable and intense interpersonal relationships, identity disturbance, impulsivity, recurrent suicidal behaviour, affective instability, chronic feelings of emptiness, inappropriate, intense anger or difficulty controlling anger and transient stress related paranoid ideation (11). The ICD-10 criteria for borderline type of emotionally unstable personality disorder are similar. The features listed in the ICD-10 are; disturbance or uncertain self image, intense and unstable relationships, efforts to avoid abandonment, recurrent threats or acts of self harm and chronic feelings of emptiness. The features of the impulsive type are also similar; marked tendency to act without consideration for consequences (impulsivity), liability to outbursts of anger or violence, unstable, capricious mood, quarrelsome behaviour and difficulty maintaining a course of action which offers no immediate reward. The last two criteria are not listed in the DSM IV.

The DSM- 5 moved from a multiaxial to a monoaxial system to remove the arbitrary difference between personality disorders and other mental disorders (12). It has retained the same categorical diagnostic criteria for personality disorders including BPD as in DSM IV. However the DSM-5 proposes an alternative hybrid dimensional-categorical model for BPD to stimulate further research 


\section{Management of borderline personality disorder}

\section{Pharmacological treatment}

Many patients with BPD are treated with medication but there is uncertainty about the usefulness of medication. Several randomized controlled trials have compared the effectiveness of antipsychotics (typical and atypical), mood stabilizers, antidepressants and combination of medication with placebo in BPD $(14,15)$. Primary outcomes in these studies were reduction in overall disorder severity as well as specific core symptoms.

We summarise below the findings of the Cochrane systematic review of randomized trials for pharmacotherapy of BPD (9).

\section{Antipsychotics}

\section{First-generation antipsychotics}

The outcome of the studies, which compared first generation antipsychotics (FGA) with placebo, showed significant reduction in anger with haloperidol and reduction in suicidal behaviour with flupentixol decanoate $(16,17,35)$. There was no difference in tolerance between FGA and placebo.

\section{Second-generation antipsychotics}

Second-generation antipsychotics (SGA) especially aripiprazole show positive effect in reduction of affective instability, anger and psychotic symptoms (18-20). They were also effective in reducing anxiety $(20,21)$. However studies show inconsistent results for reducing suicidal ideation and behaviour $(18,22)$. Open label studies report reduction in self-harming behaviour and aggression with clozapine $(23,24)$. FGA were more effective than SGA in reducing suicidal behaviour $(17,19,21)$. Both FGA and SGA were effective in anger control $(19,20)$.

\section{Mood stabilisers}

Beneficial effects were found with mood stabilisers such as semisodium valproate, lamotrigine and topiramate, but not carbamazepine $(15,25-28)$. Semisodium valproate was effective in reducing interpersonal problems and depression (15). One RCT, which compared lamotrigine with placebo, showed significant reduction in anger control and impulsivity. Lithium is licensed for the control of aggressive behaviour and intentional self-harm $(25,29)$.

\section{Antidepressants}

Several open label studies support the use of SSRI's in the reduction of impulsivity and aggression in BPD. However randomised controlled trials (RCT) show little evidence of effectiveness for antidepressant treatment. Of the different types of antidepressants only the tricyclic antidepressant amitriptyline was effective in the reduction of depressive pathology (30). No significant effect was found for SSRIs fluoxetine or fluvoxamine or the monoamine oxidase inhibitor phenelzine sulphate (31-34).

Current evidence shows that medication is effective in reducing few core symptoms of BPD and associated psychopathology. Symptoms relating to the interpersonal problems were reduced with aripiprazole and semisodium valproate $(15,19)$. Haloperidol, aripiprazole, olanzapine, and the mood stabilisers topiramate, lamotrigine and valproate semisodium are effective in treating symptoms of affective dysregulation $(15,16,18-20,22,25,-27)$. Impulsivebehavioural dyscontrol symptoms were significantly reduced by the FGA flupentixol decanoate, aripiprazole, topiramate and lamotrigine $(17,19,25-27)$. Aripiprazole and olanzapine were effective in treating cognitiveperceptual symptoms.(18-20, 22).

There is little evidence that these medications are effective in treating or controlling other BPD symptoms such as frantic efforts to avoid abandonment, chronic feelings of emptiness, identity disturbance and dissociation. These symptoms may respond better to psychotherapeutic interventions.

Patients with BPD often present in crisis with severe distress. Drug treatment is useful in controlling these acute distressing symptoms. However their usefulness in long-term treatment is questionable.

\section{Psychological treatment}

Psychotherapy is considered as first line treatment for BPD (35). Psychological therapies for BPD have many factors in common, such as a high level of structure, consistency, theoretical coherence, taking into account the relationship problems (including the difficulty in engaging positively with the therapist) and a flexible and individualized approach to care. Different types of therapies which adhere to the above principles have been developed. These can be classified as comprehensive and non comprehensive therapies. Comprehensive psychotherapies include individual psychotherapy as a substantial part of the treatment programme, non comprehensive psychotherapies do not.

The examples of comprehensive therapies are dialectical behavioural therapy (DBT), mentalisation based therapy (MBT), cognitive behavioural therapy (CBT), and interpersonal therapy (IPT) (36). DBT group skills training only, schema focused group therapy and manual-assisted cognitive therapy (MACT) are some of the non-comprehensive therapies.

We looked at the research evidence which evaluated the effectiveness of the above interventions in terms of reduction in self-harm and suicidal behaviour, improvement in psychological, interpersonal and social functioning, cost effectiveness and minimising attendance at mental health and other services. These were reported in a Cochrane review of psychological therapies for people with borderline personality disorder (35).

Of all the therapies, DBT has been studied most intensively, followed by other therapies. However, none of the therapies had a very robust evidence base and there were some concerns regarding the quality of individual studies. Not all studies primarily targeted borderline symptoms and there were considerable difference in patient characteristics, comparison groups and outcomes between the studies. Hence, the results need to be interpreted with caution. 
For DBT, there were sufficient studies to pool the results and draw conclusions, which showed significant reduction in inappropriate anger, self-harm and improvement in general functioning $(35,37-41)$. It was helpful in reducing inpatient admissions. However these studies did not support cost effectiveness of DBT although it had the potential to be cost effective (42).

\section{Mentalisation based therapy (MBT)}

The results for MBT are promising. MBT helps clients to understand the meaning of their own behaviour and that of others, and allows positive risk-taking (36). There are two studies which show significant beneficial effects on reduction of suicidality, parasuicidality, interpersonal problems and depression. $(43,44)$. It has led to real improvements in clients' progress towards a more independent life.

\section{Emotion Regulation Group Training (ERG)}

This was developed as a short-time, group-based intervention targeting emotional dysregulation among self-harming women with BPD. ERG has shown encouraging, statistically significant results in reduction in BPD severity, affective instability, impulsivity, parasuicidality, depression and anxiety $(35,45)$.

\section{Psychoanalytical therapy}

RCT of psychoanalytic orientated partial hospitalization therapy as a treatment for BPD patients show improvement of depressive symptoms and decrease in suicidal and self -mutilatory acts, reduced inpatient admissions and better interpersonal and social functioning (46).

\section{Cognitive analytical therapy}

A RCT on treatment of adolescents with BPD using cognitive analytic therapy showed reduction in borderline psychopathology, parasuicidal behaviors and improvement in social and occupational functioning (47).

Reviews suggest that some of the problems frequently encountered by people with borderline personality disorder may be amenable to talking/behavioural treatments but most therapies remain experimental and the studies are too few and small to inspire full confidence in their results. These findings require replication in larger 'real-world' studies (35).

\section{Conclusion}

Patients with BPD are very distressed by their symptoms and hence require effective treatment to ameliorate their symptoms. Some of the symptoms are amenable to pharmacological treatment in the short term but the long-term usefulness is debatable. Psychological treatment is considered as first line treatment for borderline patients but the evidence is not extensive for most of the therapies except for dialectical behavioural therapy (48). BPD is commonly associated with comorbid illness like depression and substance misuse. We believe that identifying and treating comorbid disorders would lead to a positive outcome. We suggest that developing countries should focus on collecting epidemiological data related to BPD and improve service delivery, create more awareness, identify and diagnose patients with BPD, develop treatment guidelines, and train clinicians in psychological therapies.

\section{Karthikeyan Veerasamy}

Specialty Doctor in General adult Psychiatry Worcestershire Health and care NHS Trust, United Kingdom

\section{Latha Guruvaiah}

Specialist Registrar in General Adult Psychiatry

2gether NHS Trust

Stonebow unit, Stonebow road, Hereford,

United Kingdom

Corresponding author

Karthikeyan Veerasamy

E mail: dr_vkarthikeyan@yahoo.com

\section{References}

1. Stern A. Psychoanalytic investigation of and therapy in the borderline group of neuroses. Psychoanalytic Quarterly 1938; 7:467-89.

2. 2Stoffers J, Völlm BA, Rücker G, Timmer A, Huband N, Lieb K. Drug treatment for borderline personality disorder. Cochrane summaries Published online June 2010

3. Lenzenweger MF, Lane M, Loranger AW, Kessler RC. DSM-IV personality disorders in the National Comorbidity Survey Replication (NCS-R). Biological Psychiatry 2007; 62:553-64.

4. Torgersen S. Prevalence, sociodemographics, and functional impairment. In: Oldham JM, Skodol AE, Bender DS editor(s). Essentials of Personality Disorders. 1st Edition. Arlington, VA: American Psychiatric Publishing, 2009:83-102.

5. American Psychiatric Association. Diagnostic and statistical manual of mental disorders, 4th edition, text revision. Washington, DC: American Psychiatric Association, 2000.

6. McGlashan TH, Grilo CM, Skodol AE, Gunderson JG, Shea MT, Morey LC, et al. The Collaborative Longitudinal Personality Disorders Study: baseline Axis I/II and II/II diagnostic co-occurrence. Acta Psychiatrica Scandinavica 2000; 102(4): 256-64.

7. Soloff PH, Lynch KG, Kelly TM. Childhood abuse as a risk factor for suicidal behavior in borderline personality disorder. Journal of Personality Disorder 2002; 16(3): 201-14.

8. Black DW, Blum N, Pfohl B, Hale N. Suicidal behavior in borderline personality disorder: prevalence, risk factors, prediction, and prevention. Journal of Personality Disorders 2004; 18(3): 226-39.

9. Stoffers J, Völlm BA, Rücker G, Timmer A, Huband N, Lieb K. Pharmacological interventions for borderline personality disorder. Cochrane Database of Systematic Reviews 2010, Issue 6

10. Lieb K, Zanarini MC, Schmahl C, Linehan MM, Bohus M. Borderline personality disorder. Lancet 2004; 364(9432): 453-61

11. Gelder M, Harrison P, Cowen P. Shorter Oxford Textbook of Psychiatry Oxford University Press, New York, 5th edition, 2006 Page 137 
12. American Psychiatric Association, Diagnostic and Statistical Manual of Mental Disorders by, American Psychiatric Publishing, Washington, Fifth edition, 2013: Page: 663-665, 766-767

13. Oliveira S, Barbosa I, Borges A, Lopes E, Lima C. Neural Correlates of Borderline Personality Disorder A Review. European Psychiatry, Volume 26, Issue null, Page 1036

14. Lieb K, Vollm B, Rucker G, Timmer A, Stoff ers JM. Pharmacotherapy for borderline personality disorder: Cochrane systematic review of randomised trials. Br J Psychiatry 2010; 196: 4-12.

15. Frankenburg FR, Zanarini MC. Divalproex sodium treatment of women with borderline personality disorder and bipolar II disorder: a double-blind placebocontrolled pilot study. J Clin Psychiatr2002; 63: 442-46.

16. Soloff PH, George A, Nathan RS, Schulz PM, Ulrich RF, Perel JM. Progress in pharmacotherapy of borderline disorders. Archives of General Psychiatry 1986; 43:6917.

17. Montgomery SA, Montgomery D. Pharmacological prevention of suicidal behaviour. Journal of Affective Disorders 1982; 4:291-8

18. Bogenschutz MP, Nurnberg HG. Olanzapine versus placebo in the treatment of borderline personality disorder. J Clin Psychiatry 2004; 65: 104- 9.

19. Nickel MK, Muehlbacher M, Nickel C, Kettler C, Pedrosa GF, Bachler E, et al. Aripiprazole in the treatment of patients with borderline personality disorder: a doubleblind, placebo-controlled study. American J Psychiatry 2006; 163: 833-8.

20. Eli Lilly. Efficacy and Safety of Olanzapine in Patients with Borderline Personality Disorder: A Randomized Double-blind Comparison with Placebo (summary 6253, Clinical Study Summary: Study F1D-MC-HGKK). Eli Lilly, 2007

21. Soler J, Pascual JC, Campins J, Barrachina J, Puigdemont D, Alvarez E, et al. Double-blind, placebo-controlled study of dialectical behavior therapy plus olanzapine for borderline personality disorder. American Journal of Psychiatry 2005;162:1221-4

22. Eli Lilly. Efficacy and Safety of Olanzapine in Patients with Borderline Personality Disorder: A Randomized, Flexible-dose, Double-blind Comparison with Placebo (Summary ID 6257. Clinical Study Summary: Study F1D-MC-HGKL). Eli Lilly, 200

23. Benedetti F, Sforzini L, Colombo C, Maffei C, Smeraldi E. Low dose Clozapine in acute and continuation treatment of severe Borderline personality disorder .Journal of Clinical Psychiatry, March 1998, vol./is. 59/3(103-107)

24. Chengappa, KN, Roy, Baker, Robert W, Sirri, Carlo. The successful use of clozapine in ameliorating severe self mutilation in a patient with borderline personality disorder. Journal of Personality Disorders, 1995, vol./is. 9/1(76-82)

25. 25. Tritt K, Nickel C, Lahmann C, Leiberich PK, Rother WK, Loew TH, et al. Lamotrigine treatment of aggression in female borderline-patients: a randomized, double-blind, placebo-controlled study. Journal of Psychopharmacology 2005; 19(3): 287-91

26. 26. Nickel MK, Nickel C, Mitterlehner FO, Tritt K, Lahmann C, Leiberich PK, et al. Topiramate treatment of aggression in female borderline personality disorder patients: a double-blind, placebo-controlled study. J Clin Psychiatry 2004; 65: 1515-9.
27. Nickel MK, Nickel C, Kaplan P, Lahmann C, Muhlbacher M, Tritt K, et al. Treatment of aggression with topiramate in male borderline patients: a doubleblind, placebo-controlled study. Biol Psychiatry 2005; 57: 495-9.

28. De la Fuente JM, Lotstra F. A trial of carbamazepine in borderline personality disorder. Eur Neuropsychopharmacol 1994 ; 4: 479- 86

29. 29. David Taylor, Carol Paton, Shitij Kapur. The Maudsley Prescribing Guidelines, Eleventh edition. United Kingdom:Informa publishers; 2012 page 546

30. Soloff PH, George A, Nathan S, Schulz PM, Cornelius JR, Herring J, et al. Amitriptyline versus haloperidol in borderlines: final outcomes and predictors of response. $\mathrm{J}$ Clin Psychopharmacol 1989 ; 9: 238- 46

31. Rinne T, van den Brink W, Wouter L, van Dyck R. SSRI treatment of borderline personality disorder: a randomized, placebo-controlled clinical trial for female patients with borderline personality disorder. Am J Psychiatry 2002; 159: 2048- 54.

32. Salzman C, Wolfson AN, Schatzberg A, Looper J, Henke $\mathrm{R}$, Albanese $\mathrm{M}$, et al. Effect of fluoxetine on anger in symptomatic volunteers with borderline personality disorder. J Clin Psychopharmacol 1995 ; 15: 23 - 9

33. Simpson EB, Yen S, Costello E, Rosen K, Begin A, Pistorello J, et al. Combined dialectical behavior therapy and fluoxetine in the treatment of borderline personality disorder. J Clin Psychiatry 2004 ; 65: 379- 85

34. Soloff PH, Cornelius J, George A, Nathan S, Perel JM, Ulrich RF. Efficacy of phenelzine and haloperidol in borderline personality disorder. Arch Gen Psychiatry 1993; 50: 377- 85

35. Stoffers JM, Völlm BA, Rücker G, Timmer A, Huband N, Lieb K. Psychological therapies for people with borderline personality disorder. Cochrane Database of Systematic Reviews 2012, Issue 8

36. ateman A, Fonagy P. Mentalization Based Treatment: a Practical Guide. Oxford, UK: Oxford University Press, 2006

37. Carter GL, Willcox CH, Lewin TJ, Conrad AM, Bendit N. Hunter DBT project: randomized controlled trial of dialectical behaviour therapy in women with borderline personality disorder. Australian and New Zealand Journal of Psychiatry 2010;44(2):162-73.

38. Van den Bosch LMC, Koeter MWJ, Stijnen T, Verheul R, Van den Brink W. Sustained efficacy of dialectical behaviour therapy for borderline personality disorder. Behaviour Research and Therapy 2005;43(9):1231-41.

39. Koons CR, Robins CJ, Tweed JL, Lynch TR, Gonzalez AM, Morse JQ, et al. Efficacy of dialectical behavior therapy in women veterans with borderline personality disorder. Behavior Therapy 2001;32(2):371-90.

40. Linehan MM, Heard HL, Armstrong HE. Naturalistic follow-up of a behavioral treatment for chronically parasuicidal borderline patients.[Erratum appears in Arch Gen Psychiatry 1994 May;51(5):422]. Archives of General Psychiatry 1993;50(12):971-4.

41. Linehan MM, Armstrong HE, Suarez A, Allmon D, Heard HL. Cognitive-behavioral treatment of chronically parasuicidal borderline patients. Archives of General Psychiatry 1991;48(12):1060-4.

42. Brazier J, Tumur I, Holmes M, Ferriter M, Parry G, Dent-Brown K, Paisley S. Health Technol Assess. 2006 Sep; 10(35):iii, ix-xii, 1-117

43. 43. Bateman A, Fonagy P. Effectiveness of partial hospitalization in the treatment of borderline personality 
disorder: a randomized controlled trial. American Journal of Psychiatry 1999;156(10):1563-9

44. Bateman A, Fonagy P. Randomized controlled trial of outpatient mentalization-based treatment versus structured clinical management for borderline personality disorder. American Journal of Psychiatry 2009;166(12):1355-64.

45. Gratz KL, Gunderson JG. Preliminary data on an acceptance-based emotion regulation group intervention for deliberate self-harm among women with borderline personality disorder. Behavior Therapy 2006;37(1):2535

46. Bateman A, Fonagy P. Effectiveness of partial hospitalization in the treatment of borderline personality disorder: a randomized controlled trial. American Journal of Psychiatry 1999;156(10):1563-9.

47. Andrew M. Chanen, Henry J. Jackson, Louise K. McCutcheon. Early intervention for adolescents with borderline personality disorder using cognitive analytic therapy: randomised controlled trial. The British Journal of Psychiatry (2008) 193: 477-484

48. National Collaborating Centre for Mental Health. Borderline Personality Disorder: Treatment and Management. Full Guideline. Clinical Guideline 78. NICE, 2009 (http://www.nice.org.uk/nicemedia/pdf/ CG78FullGuideline.pdf) 